\title{
Review of Practice Patterns in Post- treatment Surveillance of Primary Epithelial Ovarian Cancer
}

Authors: Joseph DeMari'1, MD; Monica Hagen Vetter ${ }^{2}$, MD; Shruthi Chandra4; John Hays, MD PhD3; Ritu Salani, MD MBA²

Department of Obstetrics and Gynecology, The Ohio State University Wexner Medical Center ${ }^{1}$; Division of Gynecologic Oncology, The Ohio State University Comprehensive Cancer Center - James Cancer Hospital and Solove Research Institute2; Division of Medical Oncology, The Ohio State University Comprehensive Cancer Center - James Cancer Hospital and Solove Research Institute; ${ }^{3}$ The Ohio State University College of Medicine ${ }^{4}$

\section{Objective}

To determine practice patterns for surveillance of primary ovarian cancer after complete response to therapy and to identify the percentage of clinicians who follow the surveillance guidelines endorsed by the Society for Gynecologic Oncology (SGO).

\section{Methods}

This is a single-institution retrospective chart review of all patients with epithelial ovarian cancer with a complete response to primary therapy between January 2012 and January 2015. Descriptive statistics were performed due to the exploratory nature of the study.

\section{Discussion}

The vast majority of patients are receiving surveillance care compliant with SGO guidelines.

Adherence to the SGO guidelines ensures costreducing surveillance as the guidelines eliminate the need for routine $\mathrm{CT}$ imaging.

\section{References}

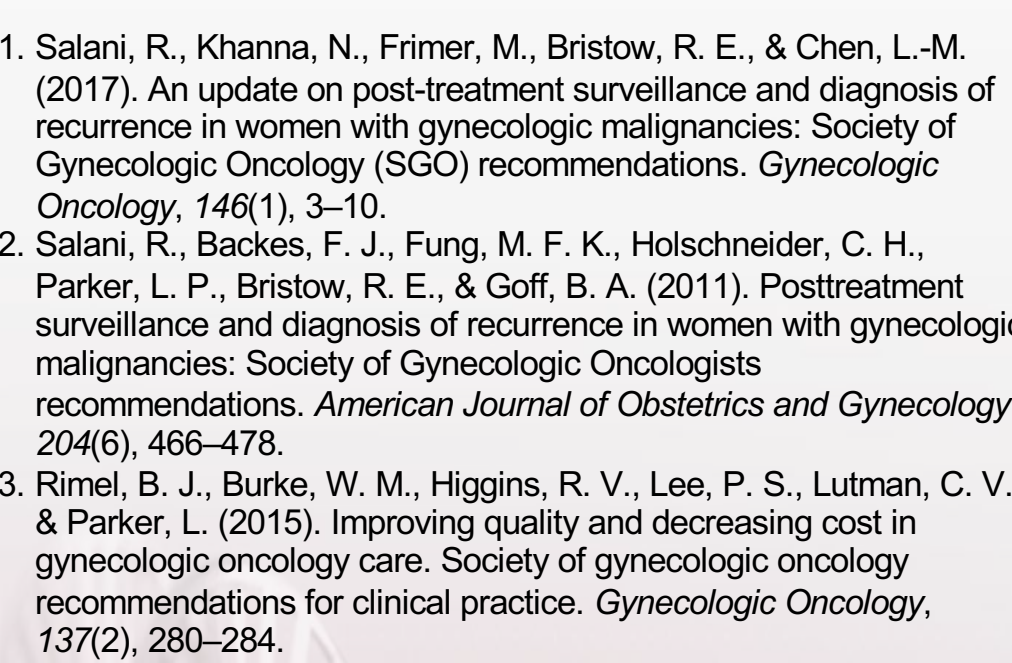

1. Salani, R., Khanna, N., Frimer, M., Bristow, R. E., \& Chen, L.-M. (2017). An update on post-treatment surveillance and diagnosis of recurrence in women with gynecologic malignancies: Society of Gynecologic Oncology (SGO) recommendations. Gynecolog Oncology, 146(1), 3-10.

Pan, R., B. Bes, F. J., Fung, M. F. K., Holschneider, C. H . sulich of Obstetrics and Gynecology, Rimel, B. J., Burke, W. M., Higgins, R. V., Lee, P. S., Lutman, C. V. \& Parker, L. (2015). Improving quality and decreasing cost in gynecologic oncology care. Society of gynecologic oncology recommendations for clinical practice. Gynecologic Oncology 137(2), 280-284.

\section{SGO Guidelines}

\begin{tabular}{|c|c|c|c|c|}
\hline & Years 0-2 & Year 2-3 & Years 3-5 & Years $>5$ \\
\hline $\begin{array}{l}\text { Review of } \\
\text { symptoms and } \\
\text { physical exam }\end{array}$ & 3-4 months & 4-6 months & 6 months & Yearly* \\
\hline $\begin{array}{l}\text { Pap test/cytologic } \\
\text { evidence }\end{array}$ & Not indicated & Not indicated & Not indicated & Not indicated \\
\hline CA-125 & Optional & Optional & Optional & Optional \\
\hline $\begin{array}{l}\text { Radiographic } \\
\text { imaging (CXR, } \\
\text { PET/CT, MRI, US) } \\
\end{array}$ & $\begin{array}{l}\text { Insufficient data } \\
\text { to support } \\
\text { routine use }\end{array}$ & $\begin{array}{l}\text { Insufficient data } \\
\text { to support routine } \\
\text { use }\end{array}$ & $\begin{array}{l}\text { Insufficient data } \\
\text { to support routine } \\
\text { use }\end{array}$ & $\begin{array}{l}\text { Insufficient data } \\
\text { to support routine } \\
\text { use }\end{array}$ \\
\hline $\begin{array}{l}\text { Recurrence } \\
\text { suspected }\end{array}$ & $\begin{array}{l}\text { CT scans or } \\
\text { PET/CT scans } \\
\text { CA-125 }\end{array}$ & $\begin{array}{l}\text { CT scans or } \\
\text { PET/CT scans } \\
\text { CA-125 }\end{array}$ & $\begin{array}{l}\text { CT scans or } \\
\text { PET/CT scans } \\
\text { CA-125 }\end{array}$ & $\begin{array}{l}\text { CT scans or } \\
\text { PET/CT scans } \\
\text { CA-125 }\end{array}$ \\
\hline
\end{tabular}

*may be followed by a gynecologist oncologist or generalist

\section{Results}

Indications for Imaging in PostTreatment Surveillance of

Primary Epithelial Ovarian Cancer

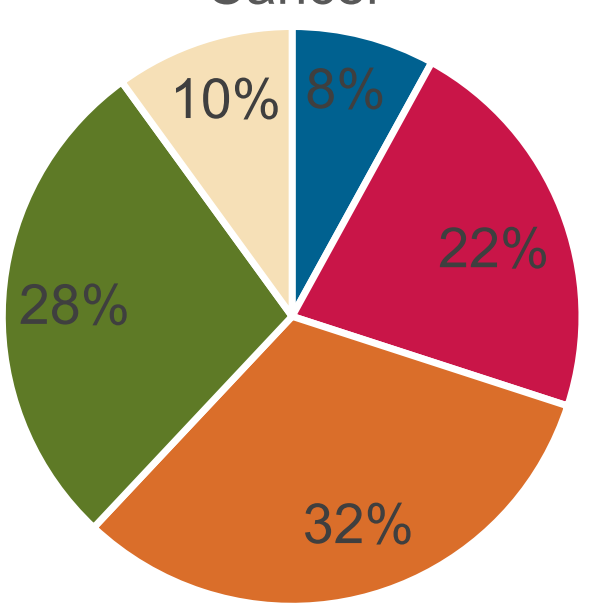

- Unknown/unindicated

- No imaging

- Elevated Ca-125 alone

- Symptoms alone

Elevated Ca-125 and symptoms

Figure 1: Shows percentage of patients that were imaged for a given indication The majority of patients were imaged due to rising Ca-125 levels, symptoms concerning for recurrence, or both.

\section{Follow-up}

- $82 \%$ had clinical follow-up scheduled according to SGO guidelines (+/- 1 month)

- Mean time to recurrence 11.8 months

\section{Compliance}

-18\% had abnormal follow-up that was non-compliant with SGO guidelines - 3/9 were due to patient initiated visits/point of access visits - 6/9 were due to unknown reasons

- Stage and histology were not associated with with non-compliance or frequency of follow-up
Method of Detection of Cancer Recurrence

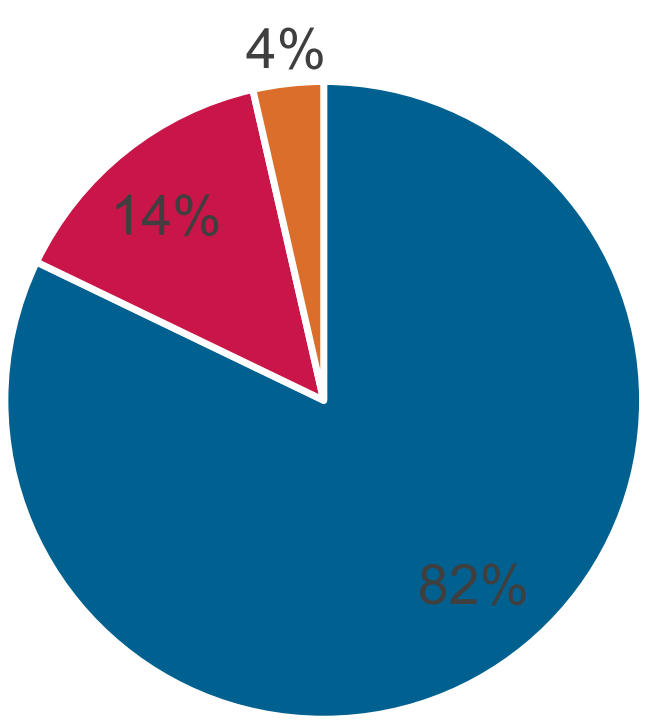

- Ca-125

- Physical exam findings

- Imaging

Figure 2: Shows method of detection of cancer recurrence. The majority of recurrence was detected via rising $\mathrm{Ca}$ 125 levels. 